\title{
Clinical predictive factors for vaginal delivery following induction of labour among pregnant women in Jordan
}

\author{
Rawan A. Obeidat ${ }^{*}$ (D), Mahmoud Almaaitah', Abeer Ben-Sadon', Dina Istaiti ${ }^{1}$, Hasan Rawashdeh', \\ Shereen Hamadneh ${ }^{2}$, Hanan Hammouri ${ }^{3}$ and Adel Bataineh ${ }^{4}$
}

\begin{abstract}
Background: Induction of labour $(\mathrm{IOL})$ is an important and common clinical procedure in obstetrics. In the current study, we evaluate predictors of vaginal delivery in both nulliparous and multiparous women in north Jordan who were induced with vaginal prostaglandins.

Method: A prospective study was conducted on 530 pregnant women at King Abdullah University Hospital (KAUH) in north Jordan. All pregnant mothers with singleton live fetuses, who had induction of labour (IOL) between July 2017 and June 2019, were included in the study. Mode of delivery, whether vaginal or caesarean, was the primary outcome. Several maternal and fetal variables were investigated. The safety and benefit of repeated dosage of vaginal prostaglandin E2 (PGE2) tablets, neonatal outcomes and factors that affect duration of labour were also evaluated. Pearson $\times 2$ test was used to investigate the significance of association between categorical variables, while student's t-test and ANOVA were applied to examine the mean differences between categorical and numerical variables. Linear regression analysis was utilized to study the relation between two continuous variables. A multivariate regression analysis was then performed. Significance level was considered at alpha less than 0.05 .

Results: Nulliparous women $(N=254)$ had significantly higher cesarean delivery rate $(58.7 \%$ vs. $17.8 \%, p<0.001)$ and longer duration of labour $(16.1 \pm 0.74 \mathrm{~h}$ vs. $11.0 \pm 0.43 \mathrm{~h}, p<0.001)$ than multiparous women $(N=276)$. In nulliparous women, the rate of vaginal delivery was significantly higher in women with higher Bishop score; the mean Bishop score was $3.47 \pm 0.12$ in nulliparous women who had vaginal delivery vs. $3.06 \pm 0.10$ in women who had cesarean delivery (Adjusted odds ratio $(\mathrm{AOR})=1.2,95 \% \mathrm{Cl}: 1.03-1.28, p=0.03$ ). In multiparous women, the rate of vaginal delivery was significantly higher in women with higher Bishop scores and lower in women with higher body mass index (BMI). The mean Bishop score was $3.97 \pm 0.07$ in multiparous women who had vaginal delivery vs. $3.56 \pm 0.16$ in women who had cesarean delivery ( $A O R=1.5,95 \% \mathrm{Cl}: 1.1-2.1, p=0.01)$. The mean $\mathrm{BMI}$ was $30.24 \pm 0.28 \mathrm{~kg} /$ $\mathrm{m}^{2}$ in multiparous women who had vaginal delivery vs. $32.36 \pm 0.73 \mathrm{~kg} / \mathrm{m}^{2}$ in women who had cesarean delivery $(\mathrm{AOR}=0.89,95 \% \mathrm{Cl}: 0.84-0.96, p=0.005) .27 \%$ of nulliparous women who received more than two PGE2 tablets and $50 \%$ of multiparous women who received more than two PGE2 tablets had vaginal delivery with no significant increase in neonatal morbidity.
\end{abstract}

\footnotetext{
*Correspondence: raobeidat3@just.edu.jo; obeidat_rawan@yahoo.com

1 Department of Obstetrics and Gynecology, Faculty of Medicine, Jordan University of Science and Technology, King Abdullah University Hospital, P. O. Box: 3030, Irbid 22110, Jordan

Full list of author information is available at the end of the article
} permits use, sharing, adaptation, distribution and reproduction in any medium or format, as long as you give appropriate credit to the original author(s) and the source, provide a link to the Creative Commons licence, and indicate if changes were made. The images or other third party material in this article are included in the article's Creative Commons licence, unless indicated otherwise in a credit line to the material. If material is not included in the article's Creative Commons licence and your intended use is not permitted by statutory regulation or exceeds the permitted use, you will need to obtain permission directly from the copyright holder. To view a copy of this licence, visit http://creativecommons.org/licenses/by/4.0/. The Creative Commons Public Domain Dedication waiver (http://creativeco mmons.org/publicdomain/zero/1.0/) applies to the data made available in this article, unless otherwise stated in a credit line to the data. 
Conclusion: Parity and cervical status are the main predictors of successful labour induction. Further studies are required to investigate the benefit of the use of additional doses of vaginal PGE2 above the recommended dose for IOL.

Keywords: Induction of labour, Parity, Prostaglandin E2, Bishop score, Cesarean section

\section{Background}

Induction of labour (IOL) is an important and common clinical procedure in obstetrics. The frequency of induction is estimated to be $15-25 \%$ [1]. IOL is usually indicated when the benefits of delivery to the mother or fetus outweigh the potential risks of continuing the pregnancy, however, the benefit of induction is not always clear. Post-term pregnancy is the most common indication for induction. There are mechanical and pharmacological methods used to induce labour. Prostaglandins have been demonstrated to be highly effective in achieving cervical ripening and vaginal delivery [2].

Induction of labour has been associated with an increased risk of cesarean delivery [3-6]. Nulliparous women are particularly at increased risk $[7,8]$. Thus, there has been considerable interest in predicting delivery outcomes in women assessed prior to IOL. Several factors have been reported to be associated with a higher chance of successful induction including a favourable cervix, multiparity, ruptured membranes, lower body mass index (BMI), taller height, younger age, increased gestational age and lower estimated fetal weight [7, 9-11].

The purpose of our study was to investigate the relevant factors for vaginal delivery among Jordanian women with prostaglandin-induced labour. The primary outcome was the rate of vaginal delivery. The secondary outcomes were time from induction to delivery and the safety of the use of additional doses of vaginal prostaglandin E2 (PGE2) tablets above the recommended dose for IOL.

\section{Material and methods Design}

A prospective study was conducted to evaluate predictors of vaginal delivery in both nulliparous and multiparous women in north Jordan who were induced with prostaglandins. The safety and benefit of repeated dosage of vaginal PGE2 tablets (Dinoprostone), neonatal outcomes and factors that affect duration of labour were also evaluated.

\section{Data collection}

Our study has been carried out at King Abdullah University Hospital (KAUH) in north Jordan. The study method and protocol were approved in May 2017 by the Institutional Review Board of the hospital (Approval no. 465/2017). The study was performed in accordance with the Code of Ethics in the Declaration of Helsinki. All pregnant women with singleton live fetuses, who had induction of labour (IOL) between July 2017 and June 2019, were included in the study. None of our patients had a previous cesarean delivery.

Written informed consents were obtained from pregnant women. Data was collected by registrars in the labour ward. The data collected include maternal age, parity, blood group, haemoglobin level, maternal weight and height, interval between last pregnancy and current pregnancy, previous miscarriages, previous preterm deliveries, previous successful induction of labour (IOL), gestational age of the fetus at the time of induction, indications for induction, Bishop score and status of the membranes (intact or ruptured) at the time of induction, membranes sweeping in the last 7 days before induction, method of induction, the dosage of PGE2 tablets received, delivery mode, duration of labour, indications of cesarean section, neonatal weight and gender, Apgar score at 1 and $5 \mathrm{~min}$ and neonatal admission to neonatal intensive care unit (NICU).

530 pregnant women were included in the study and all of them had a Bishop score of 6 or less. 461 women (87\%) were induced by vaginal administration of PGE2 tablets, 67 women $(12.6 \%)$ were induced by vaginal administration of PGE2 controlled-release pessary (Propess), and 2 women $(0.4 \%)$ were induced initially with Propess that were removed because of hyperstimulation and then PGE2 tablets were used later. All our patients were admitted to labour ward during the process of induction. Patients were induced with vaginal administration of Propess once for $24 \mathrm{~h}$ or two vaginal PGE2 tablets $(3 \mathrm{mg})$ at 6-h intervals. Some multiparous women received half a tablet $(1.5 \mathrm{mg})$. If the cervix remained unfavourable after the second dose of PGE2 tablets, some consultants performed cesarean sections while others counselled their patients regarding the administration of a third dose of PGE2; if they agreed to continue IOL then a third dose of PGE2 tablets was given; otherwise, cesarean sections were performed. Amniotomy \pm oxytocin augmentation were performed in cases with unsatisfactory progress of labour. In most patients, amniotomy was performed when cervical dilation was $\geq 2 \mathrm{~cm}$. Oxytocin was started following amniotomy and at least 4-6h after the last dose of prostaglandins. Oxytocin infusion was initiated at 1-2 milliunits/minute $(\mathrm{mU} / \mathrm{min})$ and was increased 
by $1-2 \mathrm{mU} / \mathrm{min}$ every $30 \mathrm{~min}$ until effective uterine contractions ( 3 contractions in $10 \mathrm{~min}$ lasting for $40 \mathrm{~s}$ ) were achieved or $32 \mathrm{mU} / \mathrm{min}$ was reached. Continuous electronic fetal heart rate monitoring was performed during active labour.

\section{Statistical analysis}

Statistical analysis was performed using IBM SPSS Statistics Software (v.26), 2019. Data were presented as frequency distributions for categorical variables and mean \pm standard error of the mean for continuous variables. Pearson $\chi^{2}$ test was used to investigate the significance of association between categorical variables, while student's t-test and ANOVA were applied to examine the mean differences between categorical and numerical variables. Simple linear regression analysis was utilized to study the relation between two continuous variables. After that, multivariate analysis using binary logistic regression was performed to evaluate each variable as an independent predictor of delivery mode (vaginal vs. cesarean). Adjusted Odds ratio (OR) and their corresponding 95\% confidence intervals (CI) were calculated. Multivariate analysis using a linear regression model was also performed to determine the most significant predictors for delivery duration. All variables with $p \leq 0.25$ on univariate analysis were included in the multivariate analysis. Significance level was considered at alpha less than 0.05. The Kolmogorov-Smirnov test was used to test for normality of continuous variables.

The analysis was performed for the whole group $(N=530)$ and then further analysis was performed for the subgroups: multiparous $(N=276)$ women and nulliparous $(N=254)$ women.

\section{Results}

During the study period, 530 pregnant women were admitted to the labour ward for induction of labour. Postdate was the most common indication (23.4\%) followed by rupture of membranes (premature rupture of membranes (PROM) / preterm premature rupture of membranes (PPROM) (21.1\%). The mean age of women was 29.2 years. The mean gestational age of fetuses was 39 weeks with a range of 33.3-42.4 weeks. 332 women $(62.6 \%)$ had vaginal delivery with a mean duration of labour of $12.7 \mathrm{~h}$ and 198 women (37.4\%) had cesarean section (Table 1). The mean weight of neonates was $3.1 \mathrm{~kg}$ with a range of $1.6-4.2 \mathrm{~kg}, 78$ neonates (14.7\%) were admitted to NICU, the main reason for admission was observation or treatment of infection in neonates delivered to mothers with a history of confirmed or suspected rupture of membranes more than $18 \mathrm{~h}$. The mean Apgar score at $1 \mathrm{~min}$ and $5 \mathrm{~min}$ were 7.9 and 9.1 respectively. The main indication for cesarean section was fetal
Table 1 Outcomes of induction of labour (IOL) for all women $(N=530)$

\begin{tabular}{ll}
\hline Outcome & $\begin{array}{l}\text { Frequency (\%) } \\
\text { Mean } \pm \text { SE }\end{array}$ \\
\hline Mode of delivery & \\
- Vaginal delivery & $332(62.6)$ \\
- Cesarean section & $198(37.4)$ \\
Duration of labor (hours) & $12.7 \pm 0.39$ \\
Apgar score at 1 min & $7.9 \pm 0.04$ \\
Apgar score at 5 min & $9.1 \pm 0.02$ \\
Admission to NICU & $78(14.7)$ \\
Indication for NICU admission & \\
- Observation / Antibiotics (ruptured membranes / & $63(11.9)$ \\
sepsis) & \\
- Respiratory distress (RDS / TTN) & $7(1.3)$ \\
- Low Apgar for observation & $3(0.6)$ \\
- Meconium aspiration & $1(0.2)$ \\
- Low weight for observation & $2(0.4)$ \\
- Shoulder dystocia & $1(0.2)$ \\
- Suspected TEF & $1(0.2)$ \\
Indication of cesarean sections & \\
- Fetal distress & $91(17.2)$ \\
- Failure to progress & $39(7.4)$ \\
- Failed IOL & $36(6.8)$ \\
- Maternal request & $29(5.5)$ \\
- Others & $3(0.6)$ \\
\hline
\end{tabular}

a Failed IOL: defined as the inability to achieve the active phase of labour, NICU: neonatal intensive care unit; RDS: respiratory distress syndrome; TTN: transient tachypnea of newborn; TEF: tracheoesophageal fistula; SE: standard error of the mean

distress (46\%); other indications were failure to progress (19.7\%), failed IOL (18.2\%) and maternal request (14.6\%).

Of those 530 women, 254 women $(47.9 \%)$ were nulliparous and 276 women $(52.1 \%)$ were multiparous. Compared with multiparous women, nulliparous women had significantly higher cesarean delivery rate $(58.7 \%$ vs. $17.8 \%, p<0.001$ ) and longer duration of labour $(16.1 \pm 0.74 \mathrm{~h}$ vs. $11.0 \pm 0.43 \mathrm{~h}, p<0.001)$. However, there was no significant difference in the frequency of neonatal admission to NICU and Apgar score at 1 and $5 \mathrm{~min}$. Neonatal weight $(3.2 \pm 0.03 \mathrm{~kg}$ vs. $3.0 \pm 0.03 \mathrm{~kg}, p=0.002)$ was significantly higher in the multiparous group.

\section{Mode of delivery}

\section{(A) Nulliparous $(\mathrm{N}=\mathbf{2 5 4})$}

In nulliparous women, the rate of vaginal delivery was significantly higher in women with higher Bishop score $(\mathrm{OR}=1.2,95 \% \mathrm{CI}$ : $1.03-1.28, p=0.03)$. The mean 
Bishop score was $3.47 \pm 0.12$ in nulliparous women who had vaginal delivery vs. $3.06 \pm 0.10$ in women who had cesarean delivery. Other factors were not shown to be significantly associated with mode of delivery in nulliparous women (Tables 2 and 3).

\section{(B) Multiparous $(\boldsymbol{N}=\mathbf{2 7 6})$}

In multiparous women, the rate of vaginal delivery was significantly higher in women with higher Bishop score $(\mathrm{OR}=1.5,95 \% \mathrm{CI}: 1.1-2.1, p=0.01)$ and lower in women with higher $\mathrm{BMI}(\mathrm{OR}=0.89,95 \% \mathrm{CI}$ : 0.84-0.96, $p=0.005)$. The mean Bishop score and BMI were $3.97 \pm 0.07$ and $30.24 \pm 0.28 \mathrm{~kg} / \mathrm{m}^{2}$ respectively in multiparous women who had vaginal delivery vs. $3.56 \pm 0.16$ and $32.36 \pm 0.73 \mathrm{~kg} / \mathrm{m}^{2}$ in women who had cesarean delivery. No other variables were found to be significantly associated with mode of delivery in multiparous women (Tables 2 and 3).

\section{Number of PGE2 tablets used}

\section{(A) Nulliparous $(N=231)$}

231 nulliparous women were induced by PGE2 tablets (Table 4). Of these, $37(16 \%)$ received more than two PGE2 tablets. $27 \%$ of women who received more than two PGE2 tablets had vaginal delivery. Compared with women who received two or fewer PGE2 tablets; Apgar score at 1 min was significantly better $(8.3 \pm 0.13$ vs. $7.8 \pm 0.08, p=0.007)$, there was no significant difference in Apgar score at $5 \mathrm{~min}(p=0.18)$, however, there was a more frequent, though not significant, neonatal admission to NICU ( $24.3 \%$ vs. $17.5 \%, p=0.33)$ mainly because of the higher percentage of prolonged $(>18 \mathrm{~h})$ ruptured membranes in women where more than two PGE2 tablets were used.

$$
\text { Multiparous }(N=230)
$$

As shown in Tables 4, 230 multiparous women were induced by PGE2 tablets, $22(9.6 \%)$ women received more than two PGE2 tablets. $50 \%$ of women who received more than two PGE2 tablets had vaginal deliveries. Compared with women who received two or fewer PGE2 tablets; there was no significant difference in Apgar score at $1 \mathrm{~min}(p=0.96)$ and $5 \mathrm{~min}(p=0.88)$, however, there was a more frequent, but not significant, neonatal admission to NICU $(22.7 \%$ vs. $12 \%, p=0.156)$ mainly because of the higher percentage of prolonged $(>18 \mathrm{~h})$ ruptured membranes in women where more than two PGE2 tablets were used.

\section{Duration of labour}

\section{(A) Nulliparous $(N=105)$}

105 nulliparous women had vaginal delivery, the majority of these delivered within $24 \mathrm{~h} ; 31$ women $(29.5 \%)$ gave birth within $12 \mathrm{~h}, 62$ women (59\%) within $12-24 \mathrm{~h}$ and $12(11.4 \%)$ women within $24-48 \mathrm{~h}$ from the beginning of induction.

A higher Bishop score was significantly associated with a shorter duration of labour $(P<0.001)$ in nulliparous women (Fig. 1) (Table 5).

\section{(B) Multiparous $(N=227)$}

227 multiparous women had vaginal delivery, the majority of these delivered within $12 \mathrm{~h} ; 166$ women (73.1\%) gave birth within $12 \mathrm{~h}, 50$ women $(22 \%)$ within $12-24 \mathrm{~h}$ and 11 women $(4.8 \%)$ within $24-48 \mathrm{~h}$ from the beginning of induction.

Induction to vaginal delivery time interval was significantly shorter in women with higher Bishop score $(p=0.045)$ and longer in women who had previous preterm deliveries $(p=0.049)$ (Fig. 1) (Table 5).

In both nulliparous and multiparous women, there was no significant association between induction to delivery interval and: previous miscarriages, the status of the membranes at the time of induction, membrane sweeping in the last 7 days prior to IOL, type of prostaglandins used, maternal blood group, indications of induction, neonate gender and weight, maternal age, maternal height and weight, maternal haemoglobin level, and gestational age of the fetus.

\section{Discussion}

Induction of labour is a widely used clinical procedure in obstetrics. This study was performed to evaluate maternal and fetal characteristics that independently predict a successful induction of labour, defined as vaginal delivery.

Induction of labour has been associated with an increased risk of cesarean delivery $[3-5,8]$ However, this association has been challenged in recent years [7, $12,13]$. In term and post-term pregnancies, the risk of cesarean delivery was shown to be lower among women who were induced than among those managed expectantly [13]. Also, compared with expectant management, IOL among low-risk nulliparous women at $\geq 39$ weeks was shown to be significantly associated with a lower risk of cesarean delivery, reduced risk of maternal peripartum infection and hypertensive disorders of pregnancy and lower perinatal adverse outcomes, including respiratory morbidity, intensive care unit admission, 
Table 2 Maternal and fetal variables and their association with mode of delivery in induction of labour in multiparous and nulliparous women

\begin{tabular}{|c|c|c|c|c|c|c|c|c|}
\hline \multirow[t]{2}{*}{ Variables } & \multicolumn{4}{|c|}{ Multiparous $(N=276)$} & \multicolumn{4}{|c|}{ Nulliparous ( $N=254$ ) } \\
\hline & Frequency & VD (\%) & CS (\%) & $p$-value ${ }^{\text {a }}$ & Frequency & VD (\%) & CS (\%) & $p$-value ${ }^{a}$ \\
\hline Previous miscarriage & 116 & $93(80.2)$ & $23(19.8)$ & 0.43 & 40 & $15(37.5)$ & $25(62.5)$ & 0.59 \\
\hline Previous preterm delivery & 14 & $13(92.9)$ & $1(7.1)$ & 0.29 & NA & & & \\
\hline Previous IOL & 125 & $103(82.4)$ & $22(17.6)$ & 0.83 & NA & & & \\
\hline \multicolumn{9}{|c|}{ Rupture (confirmed) of the membranes at time of induction } \\
\hline - All cases with ruptured membranes & 18 & $17(94.4)$ & $1(5.6)$ & 0.16 & 30 & $15(50)$ & $15(50)$ & 0.31 \\
\hline$\cdot$ PROM & 14 & $14(100)$ & $0(0)$ & 0.08 & 19 & $11(57.9)$ & $8(42.1)$ & 0.22 \\
\hline -PPROM & 4 & $3(75)$ & $1(25)$ & 0.77 & 11 & $4(36.4)$ & $7(63.6)$ & 0.22 \\
\hline Membranes sweeping in the last 7 days & 67 & $55(82.1)$ & $12(17.9)$ & 0.87 & 41 & $20(48.8)$ & $21(51.2)$ & 0.26 \\
\hline \multicolumn{9}{|l|}{ Method of induction used } \\
\hline - Propess & 45 & $36(80)$ & $9(20)$ & 0.10 & 22 & $11(50)$ & $11(50)$ & 0.33 \\
\hline - PGE2 tablet & 230 & $191(83)$ & $39(17)$ & & 231 & $93(40.3)$ & $138(59.7)$ & \\
\hline - Propess + PGE2 table & 1 & $0(0)$ & $1(100)$ & & 1 & $1(100)$ & $0(0)$ & \\
\hline \multicolumn{9}{|l|}{ Blood group } \\
\hline$\cdot A$ & 101 & $84(83.2)$ & $17(16.8)$ & 0.51 & 99 & $35(35.4)$ & $64(64.6)$ & 0.33 \\
\hline$\cdot A B$ & 18 & $17(94.4)$ & $1(5.6)$ & & 14 & $9(64.3)$ & $5(35.7)$ & \\
\hline$\cdot B$ & 47 & $38(80.9)$ & $9(19.1)$ & & 43 & $20(46.5)$ & $23(53.5)$ & \\
\hline$\cdot 0$ & 110 & $88(80.0)$ & $22(20.0)$ & & 98 & $41(41.8)$ & $57(58.2)$ & \\
\hline \multicolumn{9}{|l|}{ Indication for IOL } \\
\hline - Postdate & 64 & $54(84.4)$ & $10(15.6)$ & 0.32 & 60 & $25(41.7)$ & $35(58.3)$ & $0.51^{c}$ \\
\hline $\begin{array}{l}\text { - Rupture of membranes (confirmed \& sus- } \\
\text { pected) }\end{array}$ & 52 & $46(88.5)$ & $6(11.5)$ & & 60 & $27(45.0)$ & $33(55.0)$ & \\
\hline - Reduced liquor & 35 & $30(85.7)$ & $5(14.3)$ & & 42 & $15(35.7)$ & $27(64.3)$ & \\
\hline - Reduced fetal movement & 37 & $27(73.0)$ & $10(27.0)$ & & 35 & $13(37.1)$ & $22(62.9)$ & \\
\hline -SGA / IUGR & 13 & $8(61.5)$ & $5(38.5)$ & & 17 & $8(47.1)$ & $9(52.9)$ & \\
\hline • Hypertension & 14 & $12(85.7)$ & $2(14.3)$ & & 14 & $8(57.1)$ & $6(42.9)$ & \\
\hline •Thrombophilia & 13 & $11(84.6)$ & $2(15.4)$ & & 5 & $2(40.0)$ & $3(60.0)$ & \\
\hline$\cdot$ GDM / DM & 19 & $14(73.7)$ & $5(26.3)$ & & 12 & $4(33.3)$ & $8(66.7)$ & \\
\hline - Intrahepatic cholestasis of pregnancy & 6 & $6(100)$ & $0(0)$ & & 6 & $0(0)$ & $6(100)$ & \\
\hline - Antepartum haemorrhage & 3 & $3(100)$ & $0(0)$ & & 1 & $1(100)$ & $0(0)$ & \\
\hline - Others (e.g., maternal request, unstable lie, etc.) & 20 & $16(80)$ & $4(20)$ & & 2 & $1(50)$ & $1(50)$ & \\
\hline \multicolumn{9}{|l|}{ Neonate gender } \\
\hline - Male & 131 & $110(84)$ & $21(16)$ & 0.55 & 115 & $46(40.0)$ & $69(60.0)$ & 0.59 \\
\hline • Female & 145 & $117(80.7)$ & $28(19.3)$ & & 139 & $58(42.4)$ & $80(57.6)$ & \\
\hline \multirow[t]{2}{*}{ Variables } & \multicolumn{8}{|l|}{ Mean \pm SE } \\
\hline & VD & CS & & $p$-value ${ }^{b}$ & VD & CS & & $p$-value ${ }^{b}$ \\
\hline Age (years) & $32 \pm 0.33$ & $33.3 \pm 0.85$ & & 0.15 & $25.53 \pm 0.38$ & $26.23 \pm 0.32$ & & 0.17 \\
\hline Bishop score & $3.97 \pm 0.07$ & $3.59 \pm 0.16$ & & 0.033 & $3.47 \pm 0.12$ & $3.06 \pm 0.10$ & & 0.01 \\
\hline $\begin{array}{l}\text { Interval between last pregnancy and current } \\
\text { pregnancy (months) }\end{array}$ & $40.07 \pm 1.77$ & $50.57 \pm 5.72$ & & 0.09 & NA & & & \\
\hline Hemoglobin at time of $\mathrm{IOL}(\mathrm{g} / \mathrm{dl})$ & $11.06 \pm 0.08$ & $11.05 \pm 0.17$ & & 0.93 & $11.5 \pm 0.127$ & $11.7 \pm 0.08$ & & 0.19 \\
\hline Mother height $(\mathrm{cm})$ & $162.40 \pm 0.35$ & $162.86 \pm 0.76$ & & 0.67 & $161.80 \pm 0.57$ & $161.9 \pm 0.52$ & & 0.87 \\
\hline Mother weight at time of $\mathrm{IOL}(\mathrm{kg})$ & $79.7 \pm 0.75$ & $86.04 \pm 2.24$ & & 0.01 & $77.85 \pm 1.3$ & $78.7 \pm 1.1$ & & 0.61 \\
\hline Mother BMl at time of $\mathrm{IOL}\left(\mathrm{kg} / \mathrm{m}^{2}\right)$ & $30.2 \pm 0.28$ & $32.36 \pm 0.73$ & & 0.009 & $29.68 \pm 0.45$ & $30.02 \pm 0.38$ & & 0.56 \\
\hline Gestational age of the fetus (weeks) & $40.48 \pm 1.6$ & $38.67 \pm 0.25$ & & 0.60 & $38.94 \pm 0.16$ & $38.56 \pm 0.15$ & & 0.09 \\
\hline Neonate weight $(\mathrm{kg})$ & $3.17 \pm 0.03$ & $3.16 \pm 0.08$ & & 0.96 & $3.07 \pm 0.04$ & $3.02 \pm 0.04$ & & 0.35 \\
\hline
\end{tabular}

VD: vaginal delivery; CS: cesarean section; IOL: induction of labour; PGE2: prostaglandin E2; SGA: small for gestational age; IUGR: intrauterine growth restriction; GDM: gestational diabetes; DM: diabetes mellitus; SE: standard error of the mean.

a Two-sided $p$-value based on univariate analysis - Chi-square and t-test

b Two-sided $p$-value based on univariate analysis - simple linear regression

${ }^{c} p$-value $=0.036$ for nulliparous women with intrahepatic cholestasis of pregnancy 
Table 3 Multivariate analysis of factors affecting delivery mode in induction of labour

\begin{tabular}{|c|c|c|c|}
\hline Factors & $\mathrm{OR}^{\mathrm{a}}$ & $95 \% \mathrm{Cl}$ & $p$-value ${ }^{b}$ \\
\hline \multicolumn{4}{|l|}{ Nulliparous } \\
\hline Age (years) & 0.95 & $0.86-1.01$ & 0.12 \\
\hline Hemoglobin at time of $\mathrm{IOL}(\mathrm{g} / \mathrm{dl})$ & 0.82 & $0.65-1.01$ & 0.07 \\
\hline Gestational age of the fetus (weeks) & 1.12 & $0.95-1.31$ & 0.18 \\
\hline Bishop Score & 1.23 & $1.03-1.28$ & 0.03 \\
\hline Status of the membrane at the time of induction & 1.1 & $0.69-1.6$ & 0.27 \\
\hline Indication for induction - Intrahepatic cholestasis of pregnancy & 0.1 & $0.67-1.49$ & 0.79 \\
\hline \multicolumn{4}{|l|}{ Multiparous } \\
\hline Maternal BMl at time of $\mathrm{IOL}\left(\mathrm{kg} / \mathrm{m}^{2}\right)$ & 0.89 & $0.84-0.96$ & 0.005 \\
\hline Bishop Score & 1.5 & $1.1-2.1$ & 0.01 \\
\hline Interval between last pregnancy and current pregnancy (months) & 0.99 & $0.98-1.0$ & 0.19 \\
\hline Method of induction used & 1.1 & $0.46-2.8$ & 0.97 \\
\hline Status of the membrane at time of induction & 0.14 & $0.15-1.2$ & 0.72 \\
\hline
\end{tabular}

$\mathrm{Cl}$ : confidence interval; IOL: induction of labour, BMI: body mass index.

a OR: odds ratio of vaginal delivery

b Two-sided $p$-value based on binary logistic regression adjusted for all factors shown

Table 4 Outcomes of induction of labour in both multiparous and nulliparous women $(N=461)$ and their relation to the number of prostaglandins E2 tablets used

\begin{tabular}{|c|c|c|c|c|c|c|c|}
\hline \multirow[t]{2}{*}{ Number of PGE2 tablets } & & \multicolumn{3}{|c|}{ Multiparous $(\mathrm{N}=230)$} & \multicolumn{3}{|c|}{ Nulliparous $(N=231)$} \\
\hline & & $\leq 2$ tablets & $>2$ tablets & $p$-value ${ }^{a}$ & $\leq 2$ tablets & $>2$ tablets & $p$-value ${ }^{a}$ \\
\hline \multicolumn{8}{|l|}{ Frequency (\%) } \\
\hline Women induced with PGE2 tablets & & $208(90.4)$ & $22(9.6)$ & NA & $194(84)$ & $37(16)$ & NA \\
\hline \multirow[t]{2}{*}{ Mode of delivery } & VD & $180(86.5)$ & $11(50)$ & $<0.001$ & $83(42.8)$ & $10(27)$ & 0.073 \\
\hline & CS & $28(13.5)$ & $11(50)$ & & $111(57.2)$ & $27(73)$ & \\
\hline Admission to neonatal intensive care unit & & $25(12)$ & $5(22.7)$ & 0.156 & $34(17.5)$ & $9(24.3)$ & 0.33 \\
\hline \multicolumn{8}{|l|}{ Mean \pm SE } \\
\hline Apgar score at $1 \mathrm{~min}$ & & $8.0 \pm 0.05$ & $8.0 \pm 0.26$ & 0.96 & $7.8 \pm 0.08$ & $8.3 \pm 0.13$ & 0.007 \\
\hline Apgar score at $5 \mathrm{~min}$ & & $9.1 \pm 0.04$ & $9.1 \pm 0.11$ & 0.88 & $9.0 \pm 0.04$ & $9.2 \pm 0.09$ & 0.18 \\
\hline
\end{tabular}

a Two-sided $p$-value based on univariate analysis - Chi-square and t-test

PGE2: prostaglandin E2; SE: standard error of the mean; VD: vaginal delivery; CS: cesarean section.

and mortality [14-16]. A vaginal delivery rate of $62.6 \%$ was reported in our study and is lower than the rates observed in most of the studies in the literature [2]. However, some studies showed low vaginal birth rates, for example, Osmundson et al. reported a $56.9 \%$ vaginal delivery rate among induced nulliparous women [16]; similarly, a vaginal delivery rate of $68.4 \%$ was reported in a prospective study in China [17]. Our low vaginal birth rate could be because our institution (KAUH) is a tertiary referral centre receiving high-risk pregnancies. Moreover, $14.6 \%$ of cesarean deliveries were on maternal request and possibly further patients counselling by health care providers regarding IOL should be encouraged in our institution.
Parity is the most important variable implicated in a successful IOL. Studies are consistent in demonstrating higher success rates of induction in multiparous compared to nulliparous women [5, 18-26]. Our study agrees with existing literature that 'multiparity' is linked with the success of IOL and showed a vaginal delivery of $82.2 \%$ among multiparous women vs. $41.3 \%$ among nulliparous women.

Higher Bishop score in our study was a protective factor for vaginal delivery in both nulliparous and multiparous group. Bishop score is one of the best available tools for assessing cervical status $[5,11]$. Most studies reported an inverse relationship between Bishop score and failure of labour induction, with low scores being 
(A) Nulliparous women

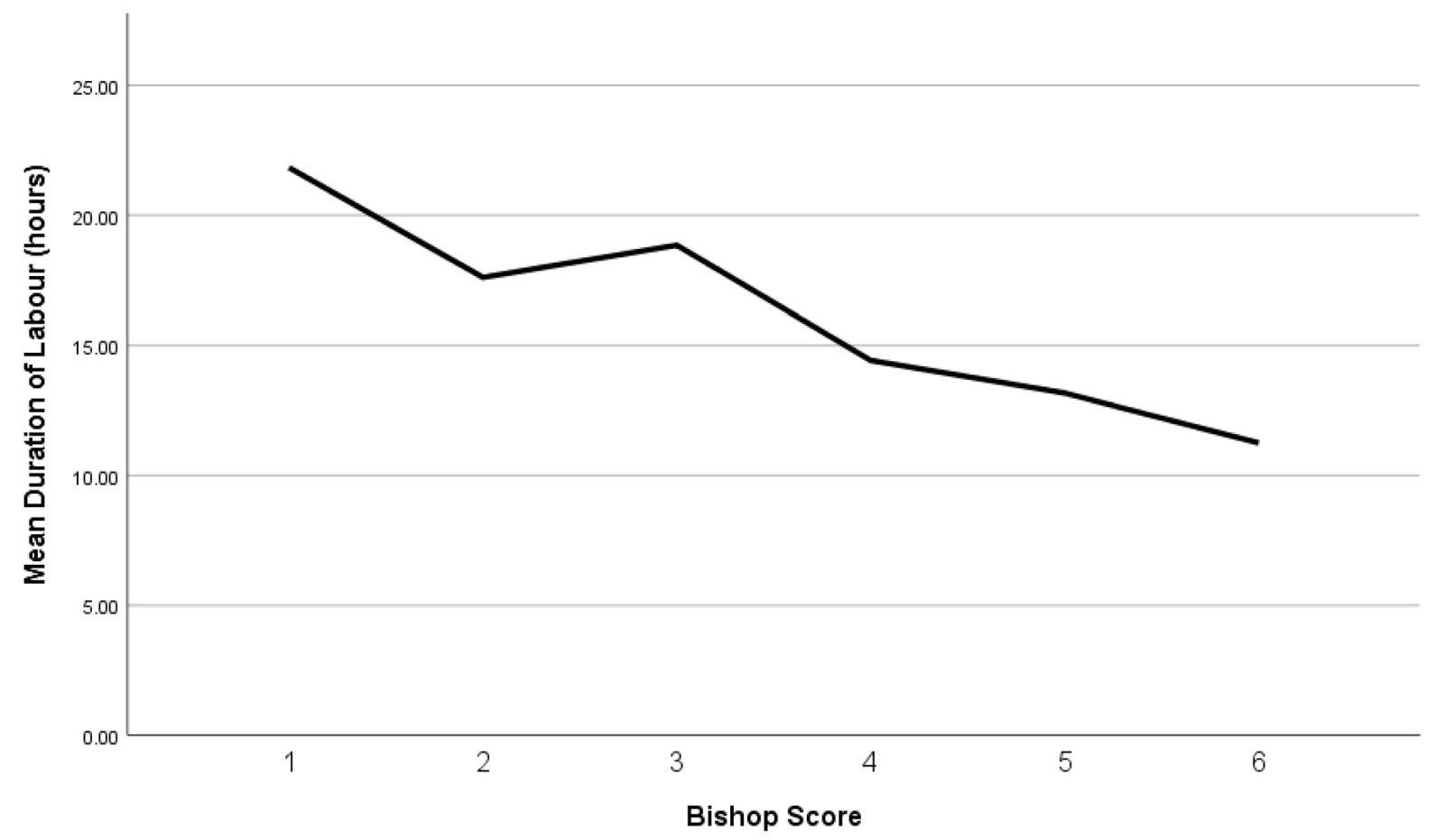

(B) Multiparous women

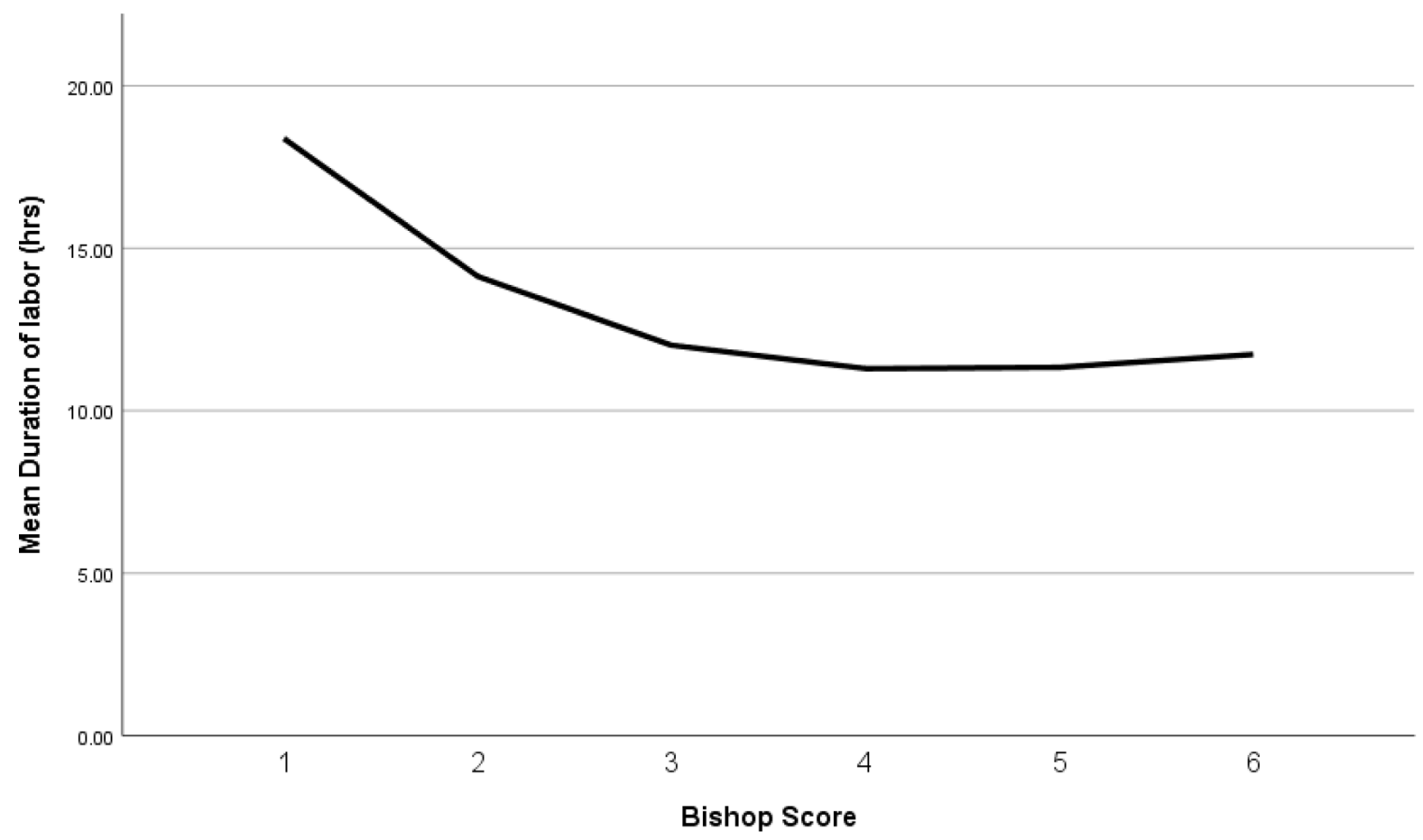

Fig. 1 The relation between Bishop score and duration of labour in nulliparous and multiparous women 
Table 5 Multivariate analysis of factors affecting delivery duration in induction of labour

\begin{tabular}{|c|c|c|c|c|c|}
\hline Predictor & $\begin{array}{l}\text { Unstandardized } \\
\text { Coefficients }(\beta)\end{array}$ & $\begin{array}{l}\text { Standardized } \\
\text { Coefficients (Beta) }\end{array}$ & Standard Error & $p$-value ${ }^{\text {a }}$ & $95 \% \mathrm{Cl}$ \\
\hline \multicolumn{6}{|l|}{ Nulliparous } \\
\hline Bishop score & -2.1 & -0.337 & 0.58 & $<0.001$ & $-3.25--1.03$ \\
\hline \multicolumn{6}{|l|}{ Multiparous } \\
\hline Bishop score & -0.85 & -0.133 & 0.421 & 0.045 & $-1.70--0.030$ \\
\hline Previous preterm delivery & 3.65 & 0.132 & 1.81 & 0.049 & $0.07-7.23$ \\
\hline
\end{tabular}

${ }^{a}$ Two-sided $p$-value based on multivariate analysis - linear regression

$\mathrm{Cl}$ : confidence interval.

associated with a higher cesarean delivery rate $[1,3,5$, $7,18,19,22,24,25,27]$ and longer induction to vaginal delivery time interval [23]. However, other studies reported that Bishop score was a poor predictor of the outcome of labour in women scheduled for induction $[23,28,29]$.

Body mass index is an important parameter in clinical practice. In our study, lower maternal weight and BMI were predictive of vaginal delivery in multiparous women but not in nulliparous women. In the literature, higher BMI was reported to be associated with a longer duration of labour $[19,20,28]$ and a higher cesarean delivery rate $[1,3,5-7,11,20,24,27,28]$. On the contrary, other studies showed that weight and BMI did not influence the likelihood of successful induction [18, 23, 27].

Maternal height has been identified by some investigators as predictive of vaginal delivery; taller women were reported to have a better chance of success for IOL $[7,9-11,19]$. However other studies showed no effect of maternal height on the likelihood of successful induction [23]. Our study reported no association between maternal height and the mode of delivery in both nulliparous and multiparous women.

Younger maternal age was found to be predictive of the success of IOL in many studies $[3,5,7,11,18,19$, $25]$ but not in the other studies [1, 26, 27]. In our study, elder maternal age was significantly associated with a higher vaginal delivery rate in the whole sample, but this significance disappeared when adjusted for parity. Analysis of subgroups showed that maternal age is not an independent predictor of IOL in both nulliparous and multiparous group.

Characteristics of the fetus or neonate may also influence the success of induction. Successful induction was reported to be associated with increased gestational age $[7,13,19,23]$ and lower birth weight $[5,7,11,18,19,21$, $23,24]$. However, in our study and other studies fetal gestational age $[1,26]$ and neonatal weight $[26-28]$ were not predictors of success of induction.
Rupture of membranes has been reported to be associated with a higher chance of successful induction. Though, in other studies membranes status was not associated with successful labour induction [11]. In our study, neither all cases of ruptured membranes (confirmed by clinical exam + suspected cases based on history but not confirmed by exam) nor confirmed cases of ruptured membranes were associated with the success of induction. Sub-analysis of term and preterm pregnancies showed similar results (Table 2).

In the current study, there was no difference in the rate of vaginal delivery between controlled-release pessary (Propess) and vaginal PGE2 tablet. Similarly, A Cochrane review conducted by Thomas et al. reported no evidence of differences in vaginal delivery rates with $24 \mathrm{~h}$ and cesarean section rates between PGE2 controlled-release pessary and either vaginal PGE2 tablet or gel [2]. The oral administration of PGE2 tablets is not authorized in our institution as studies showed it was no more effective in achieving vaginal delivery than other routes, had more frequent gastrointestinal adverse effects and there was no clear evidence favouring its use regarding the safety of women and fetuses [30-32]. Alike, misoprostol use for labour induction is not licensed in our institution, however, the oral use of low dose misoprostol has been recommended by many studies. In a Cochrane review conducted by Alfirevic et, a total of 3240 women were randomised to oral misoprostol or vaginal dinoprostone in 10 trials, and the results showed no statistically significant differences between the two groups in any of the following outcomes: achieving vaginal birth within $24 \mathrm{~h}$, cesarean birth rates and uterine hyperstimulation rates [32]. Moreover, other studies favour the use of oral misoprostol and they revealed that although oral misoprostol was associated with a longer induction to vaginal delivery interval than vaginal PGE2 [33, 34], it was safer, since it resulted in fewer cesarean sections [33-35] and less uterine hyperstimulation with fetal heart changes [34, 35]. 
In our study, there was no significant association between history of membrane stripping in the last week and the rate of vaginal delivery in IOL. We recognized that part of women who had sweeping had spontaneous labour and they did not need IOL. Stripping of the membranes is associated with a reduced frequency of post-term pregnancies [36-38] and should not be discouraged.

There is no full agreement on the ideal dosage of PGE2 that should be used in IOL. The National Institute for Health and Care Excellence (NICE) recommended regimen for IOL by PGE2 tablets is a maximum of two doses $6 \mathrm{~h}$ apart [30]. Our study showed that, reassuringly, the use of additional doses of PGE2 tablets above the recommended dose for induction of labour was not associated with increased neonatal morbidity and nearly a third of nulliparous women and a half of multiparous women achieved vaginal delivery. Similarly, two recent retrospective studies showed that repeated doses of vaginal PGE2 for IOL above the current recommendations was associated with a higher vaginal delivery rate without compromising neonatal wellbeing for both nulliparous and multiparous women $[39,40]$.

\section{Study limitation}

Our study group includes women with both complicated and uncomplicated pregnancies, term and preterm pregnancies, intact and ruptured membranes, different methods of induction (PGE2 tablets and Propess) and different indications for IOL. Having a heterogeneous study group may be considered a drawback, however, it allowed us to evaluate many factors in their association with IOL and also we consider our results as reliable due to the use of suitable statistical analysis. Another limitation is that maternal morbidity was not fully assessed in our study.

\section{Conclusion}

Despite the large number of studies performed, there are still many controversies regarding factors implicated in a successful IOL. Parity and cervical status are the main predictors of successful labour induction. Improving the prediction of induction failure is currently a major challenge in obstetrics and is mandatory to improve IOL management and outcome. IOL for inappropriate indication should be discouraged especially before 39 weeks and in nulliparous women with an unfavourable cervix.

Further studies are required to investigate the benefit of the use of additional doses of vaginal PGE2 above the recommended dose for IOL.

\section{Acknowledgements}

We appreciated all the study participants and hospital workers who participated in this work.

\section{Data availability}

The datasets used and/or analyses during the current study are available from the corresponding author on reasonable request.

\section{Authors' contributions}

RO designed the study, carried out the statistical analysis, and wrote the manuscript. MA, ABS, and DI collected the data. HH carried out the statistical analyses. HR, SH and AB participated in the study design and helped in drafting the manuscript. All authors have read and approved the final manuscript.

\section{Funding}

No fund.

\section{Declarations}

Ethics approval and patient consent

The study method and protocol were approved by the Institutional Review Board of King Abdullah University Hospital. Written informed consents were obtained from pregnant women. The study was performed in accordance with the Code of Ethics in the Declaration of Helsinki.

\section{Conflict of interest}

The authors declare no potential conflicts of interest.

\section{Consent for publication}

Not applicable.

\section{Author details}

${ }^{1}$ Department of Obstetrics and Gynecology, Faculty of Medicine, Jordan University of Science and Technology, King Abdullah University Hospital, P. O. Box: 3030, Irbid 22110, Jordan. ${ }^{2}$ Department of Maternal and Child Health, Al Al-Bayt University, Mafraq, Jordan. ${ }^{3}$ Department of Mathematics and Statistics, Jordan University of Science and Technology, Irbid, Jordan. ${ }^{4}$ Department of Anesthesia, Jordan University of Science and Technology, Irbid, Jordan.

Received: 6 November 2020 Accepted: 23 September 2021 Published online: 07 October 2021

\section{References}

1. Riboni F, Garofalo G, Pascoli I, Vitulo A, Dell'avanzo M, Battagliarin G, et al. Labour induction at term: clinical, biophysical and molecular predictive factors. Arch Gynecol Obstet. 2012;286(5):1123-9. https://doi.org/10. 1007/s00404-012-2432-1.

2. Thomas J, Fairclough A, Kavanagh J, Kelly AJ. Vaginal prostaglandin (PGE2 and PGF2a) for induction of labour at term. Cochrane Database Syst Rev. 2014 Jun 19;2014(6):CD003101. doi: https://doi.org/10.1002/14651858. CD003101.pub3. PMID: 24941907; PMCID: PMC7138281.

3. Vrouenraets FPJM, Roumen FJME, Dehing CJG, van den Akker ESA, Aarts MJB, Scheve EJT. Bishop score and risk of cesarean delivery after induction of labor in nulliparous women. Obstet Gynecol. 2005;105:690-7. https://doi.org/10.1097/01.AOG.0000152338.76759.38.

4. Yeast JD, Jones A, Poskin M. Induction of labor and the relationship to cesarean delivery: a review of 7001 consecutive inductions. Am J Obstet Gynecol. 1999;180:628-33. https://doi.org/10.1016/S0002-9378(99) 70265-6.

5. Teixeira C, Lunet N, Rodrigues T, Barros H. The bishop score as a determinant of labour induction success: a systematic review and metaanalysis. Arch Gynecol Obstet. 2012;286:739-53. https://doi.org/10.1007/ s00404-012-2341-3.

6. NADER R, SHEK KL, DIETZ HP. Predicting the outcome of induction of labour. Aust N Z J Obstet Gynaecol. 2010;50:329-33. https://doi.org/10.1111/j.1479828X.2010.01169.x

7. Tolcher MC, Holbert MR, Weaver AL, McGree ME, Olson JE, El-Nashar $\mathrm{SA}$, et al. Predicting cesarean delivery after induction of labor among 
nulliparous women at term. Obstet Gynecol. 2015;126:1059-68. https://doi. org/10.1097/AOG.0000000000001083.

8. Cammu H, Martens G, Ruyssinck G, Amy J-J. Outcome after elective labor induction in nulliparous women: a matched cohort study. Am J Obstet Gynecol. 2002;186:240-4. https://doi.org/10.1067/mob.2002.119643.

9. Gibson KS, Waters TP. Measures of success: prediction of successful labor induction. Semin Perinatol. 2015;39:475-82. https://doi.org/10.1053/j.sempe ri.2015.07.012.

10. Pevzner L, Rayburn WF, Rumney P, Wing DA. Factors predicting successful labor induction with Dinoprostone and misoprostol vaginal inserts. Obstet Gynecol. 2009;114:261-7. https://doi.org/10.1097/AOG.0b013e3181ad9377.

11. CRANE JMG. Factors predicting labor induction success: a critical analysis. Clin Obstet Gynecol. 2006;49:573-84. https://doi.org/10.1097/00003081200609000-00017.

12. Baños N, Migliorelli F, Posadas E, Ferreri J, Palacio M. Definition of failed induction of labor and its predictive factors: two unsolved issues of an everyday clinical situation. Fetal Diagn Ther. 2015;38:161-9. https://doi.org/ 10.1159/000433429.

13. Mishanina E, Rogozinska E, Thatthi T, Uddin-Khan R, Khan KS, Meads C. Use of labour induction and risk of cesarean delivery: a systematic review and meta-analysis. Can Med Assoc J. 2014;186:665-73. https://doi.org/10.1503/ cmaj.130925.

14. Grobman WA, Caughey AB. Elective induction of labor at 39 weeks compared with expectant management: a meta-analysis of cohort studies. Am J Obstet Gynecol. 2019;221:304-10. https://doi.org/10.1016/j.ajog.2019.02. 046.

15. Grobman WA, Rice MM, Reddy UM, Tita ATN, Silver RM, Mallett G, et al. Labor induction versus expectant Management in low-Risk Nulliparous Women. N Engl J Med. 2018;379:513-23. https://doi.org/10.1056/NEJMoa1800566.

16. Osmundson S, Ou-Yang RJ, Grobman WA. Elective induction compared with expectant Management in Nulliparous Women with an unfavorable cervix. Obstet Gynecol. 2011;117:583-7. https://doi.org/10.1097/AOG.0b013e3182 Ocaf12.

17. Du C, Liu Y, Liu Y, Ding H, Zhang R, Tan J. Double-balloon catheter vs. dinoprostone vaginal insert for induction of labor with an unfavorable cervix Arch Gynecol Obstet 2015 Jun;291 (6):1221-7. doi: 10.1007/s00404-0143547-3. Epub 2014 Nov 19. PMID: 25408273

18. Batinelli L, Serafini A, Nante N, Petraglia F, Severi FM, Messina G. Induction of labour: clinical predictive factors for success and failure. J Obstet Gynaecol. 2018;38:352-8. https://doi.org/10.1080/01443615.2017.1361388.

19. Crane J, Delaney T, Butt K, Bennett K, Hutchens D, Young D. Predictors of successful labor induction with oral or vaginal misoprostol. J Matern Fetal Neonatal Med. 2004;15:319-23. https://doi.org/10.1080/147670504100017 02195.

20. Lassiter JR, Holliday N, Lewis DF, Mulekar M, Abshire J, Brocato B. Induction of labor with an unfavorable cervix: how does BMl affect success? J Matern Fetal Neonatal Med. 2015:1-3. https://doi.org/10.3109/14767058.2015. 1112371.

21. Zhao $L$, Lin $Y$, Jiang $T$, Wang $L$, Li M, Wang $Y$, et al. Vaginal delivery among women who underwent labor induction with vaginal dinoprostone (PGE2) insert: a retrospective study of 1656 women in China. J Matern Fetal Neonatal Med. 2019;32:1721-7. https://doi.org/10.1080/14767058.2017.1416351.

22. Bueno B, San-Frutos L, Salazar F, Pérez-Medina T, Engels V, Archilla B, et al. Variables that predict the success of labor induction. Acta Obstet Gynecol Scand. 2005;84:1093-7. https://doi.org/10.1111/j.0001-6349.2005.00881.x.

23. Wing DA, Tran S, Paul RH. Factors affecting the likelihood of successful induction after intravaginal misoprostol application for cervical ripening and labor induction. Am J Obstet Gynecol. 2002;186:1237-43. https://doi.org/10. 1067/mob.2002.123740.

24. Favilli A, Acanfora MM, Bini V, Radicchi R, di Renzo GC, Gerli S. Single indication of labor induction with prostaglandins: is advanced maternal age a risk factor for cesarean section? A matched retrospective cohort study. J Matern Fetal Neonatal Med. 2013;26:665-8. https://doi.org/10.3109/14767058.2012. 746658.

25. Chandra S. Transvaginal ultrasound and digital examination in predicting successful labor induction. Obstet Gynecol. 2001;98:2-6. https://doi.org/10. 1016/S0029-7844(01)01386-2.
26. Bueno B, San-Frutos L, Pérez-Medina T, Barbancho C, Troyano J, Bajo J. The labor induction: integrated clinical and sonographic variables that predict the outcome. J Perinatol. 2007;27:4-8. https://doi.org/10.1038/sj.jp.7211619.

27. Grobman WA, Simon C. Factors associated with the length of the latent phase during labor induction. European Journal of Obstetrics \& Gynecology and Reproductive Biology. 2007;132:163-6. https://doi.org/10.1016/j.ejogrb. 2006.09.002.

28. Uyar Y, Erbay G, Demir BC, Baytur Y. Comparison of the bishop score, body mass index and transvaginal cervical length in predicting the success of labor induction. Arch Gynecol Obstet 2009;280:357-62. doi: 10.1007/ s00404-008-0915-x.[29].

29. Kolkman D, Verhoeven C, Brinkhorst S, van der Post J, Pajkrt E, Opmeer B, et al. The bishop score as a predictor of labor induction success: a systematic review. Am J Perinatol. 2013;30:625-30. https://doi.org/10.1055/s-00321331024.

30. National Collaborating Centre for Women's and Children's Health (UK); July 2008, http://www.nice.org.uk/nicemedia/pdf/CG070NICEGuideline.pdf. n.d

31. French L. Oral prostaglandin E2 for induction of labour. Cochrane Database Syst Rev 2001;(2):CD003098. doi: 10.1002/14651858.CD003098. PMID: 11406075.

32. Alfirevic Z, Aflaifel N, Weeks A. Oral misoprostol for induction of labour. Cochrane Database Syst Rev. 2014 Jun 13;2014(6):CD001338. doi: 10.1002/14651858.CD001338.pub3. PMID: 24924489; PMCID: PMC6513439.

33. Thorbiörnson A, Vladic T, Stjernholm YV. Oral versus vaginal prostaglandin for labor induction. J Matern Fetal Neonatal Med 2017 Apr;30(7):789-792. doi: 10.1080/14767058.2016.1190823. Epub 2016 Jun 13. PMID: 27186795.

34. Chen W, Xue J, Peprah MK, Wen SW, Walker M, Gao Y, Tang Y. A systematic review and network meta-analysis comparing the use of Foley catheters, misoprostol, and dinoprostone for cervical ripening in the induction of labour. BJOG. 2016 Feb;123(3):346-54. doi: 10.1111/1471-0528.13456. Epub 2015 Nov 5. PMID: 26538408.

35. Alfirevic Z, Keeney E, Dowswell T, Welton NJ, Medley N, Dias S, Jones LV, Caldwell DM. Methods to induce labour: a systematic review, network metaanalysis and cost-effectiveness analysis. BJOG. 2016 Aug;123(9):1462-70. doi: 10.1111/1471-0528.13981. Epub 2016 Mar 22. PMID: 27001034; PMCID: PMC5021158

36. Mozurkewich EL, Chilimigras JL, Berman DR, Perni UC, Romero VC, King VJ, et al. Methods of induction of labour: a systematic review. BMC Pregnancy and Childbirth. 2011;11:84. https://doi.org/10.1186/1471-2393-11-84.

37. Yildirim G, Güngördük K, Karadağ ÖI, Aslan H, Turhan E, Ceylan Y. Membrane sweeping to induce labor in low-risk patients at term pregnancy: a randomised controlled trial. J Matern Fetal Neonatal Med. 2010;23:681-7. https://doi.org/10.3109/14767050903387078.

38. de Miranda E, van der Bom J, Bonsel G, Bleker O, Rosendaal F. Membrane sweeping and prevention of post-term pregnancy in low-risk pregnancies: a randomised controlled trial. BJOG: An International Journal of Obstetrics and Gynaecology. 2006;113:402-8. https://doi.org/10.1111/j.1471-0528. 2006.00870.x.

39. Ayaz H, Black M, Madhuvrata P, Shetty A. Maternal and neonatal outcomes following additional doses of vaginal prostaglandin E2 for induction of labour: a retrospective cohort study. European Journal of Obstetrics and Gynecology and Reproductive Biology. 2013;170:364-7. https://doi.org/10. 1016/j.ejogrb.2013.07.021.

40. Amer S, Rawashdeh H, Alshdaifat E, Altal O, Yaseen H, Alhowary A. The association between repeated doses of vaginal PGE2 (Dinoprostone, Prostin ${ }^{\circledR}$ ) and both maternal and neonatal outcomes among women in the north of Jordan. Clinical and Experimental Obstetrics \& Gynecology. 2020;47, 329. https://doi.org/10.31083/j.ceog.2020.03.5322.

\section{Publisher's Note}

Springer Nature remains neutral with regard to jurisdictional claims in published maps and institutional affiliations. 